\title{
The Profitability of Contrarian Stock Pairs Identified Using a Partial Adjustment Model: An Evaluation of Chinese and Australian Stocks
}

\author{
Santosh Mon Abraham ${ }^{1}$ \\ ${ }^{1}$ School of Economics and Finance, Curtin University, Australia \\ Correspondence: Santosh Mon Abraham, School of Economics and Finance, Curtin University, Bentley, W.A., \\ 6845, Australia. E-mail: santosh.monabraham@gmail.com
}

Received: September 9, 2013

Accepted: October 10, 2013

Online Published: October 26, 2013

doi:10.5539/ijef.v5n11p82

URL: http://dx.doi.org/10.5539/ijef.v5n11p82

\begin{abstract}
This paper studies two contrarian strategy; one based on the Law of One Price (LOP) and another based on the Markov switching strategy. The stock pairs are identified using a new derivation of the partial adjustment model (PAM), cointegration and Markov switching is applied to the pairs. The Markov strategy is more profitable than the LOP strategy. Both are profitable and their portfolios are combined in different proportions in the efficient frontier. The optimal portfolio is calculated. Cointegration implies short-term divergence and long-term convergence, therefore these stocks are inefficient in the short-run, but they are efficient in the long-run, providing support to Wilson and Marasdeh (2007).
\end{abstract}

Keywords: international arbitrage, pairs-trading, cointegration, partial adjustment model

\section{Introduction}

A contrarian strategy is comprised of buying stocks which have performed poorly in the past and selling stocks which have performed well in the past. De Bondt and Thaler $(1985,1987)$ find that in the past three to five years the losers outperform the previous winners by nearly $25 \%$ in the following three to five years. There are alternatives which have been proposed to explain this outcome: (1) the losers are generally stocks with small capitalisations and overreaction is a characteristic for small firms. Zarowin (1990) and Chopra et al. (1992) investigated the size effect and state that when size is taken into account, the returns of the losers are diminished. However, they state that larger firms are efficient. (2) Chan (1988) and Ball and Kothari (1989) state that time-varying risk has been neglected. Ball and Kothari (1989) show that the risk premia of the losers are greater than those of the winners in the period after the formation of the portfolios; explaining the differences in the returns between losers and winners.

In this paper, we investigate the profitability of the international contrarian strategy through a pairs-trading approach in the Chinese and Australian stock market. There are a limited number of studies of investment strategies in the Chinese market and fewer studies investigating international arbitrage between China and Australia, despite the fact that China is one of the fastest growing economies in the world and an emerging super-power. The work is motivated by the desire to scrutinise the Chinese-Australian economic relationship and to exploit these opportunities for profit. There has been a growing economic and trading relationship between the two nations. China's demand for metals, minerals and energy products has witnessed growing and favourable terms of trade for Australia. China too has benefitted as it has used Australian iron ore and coal to urbanise, industrialise and manufacture goods for export. Figure 1 Show the growing terms of trade for Australian trade with China compared to its trade with the rest of the world. 


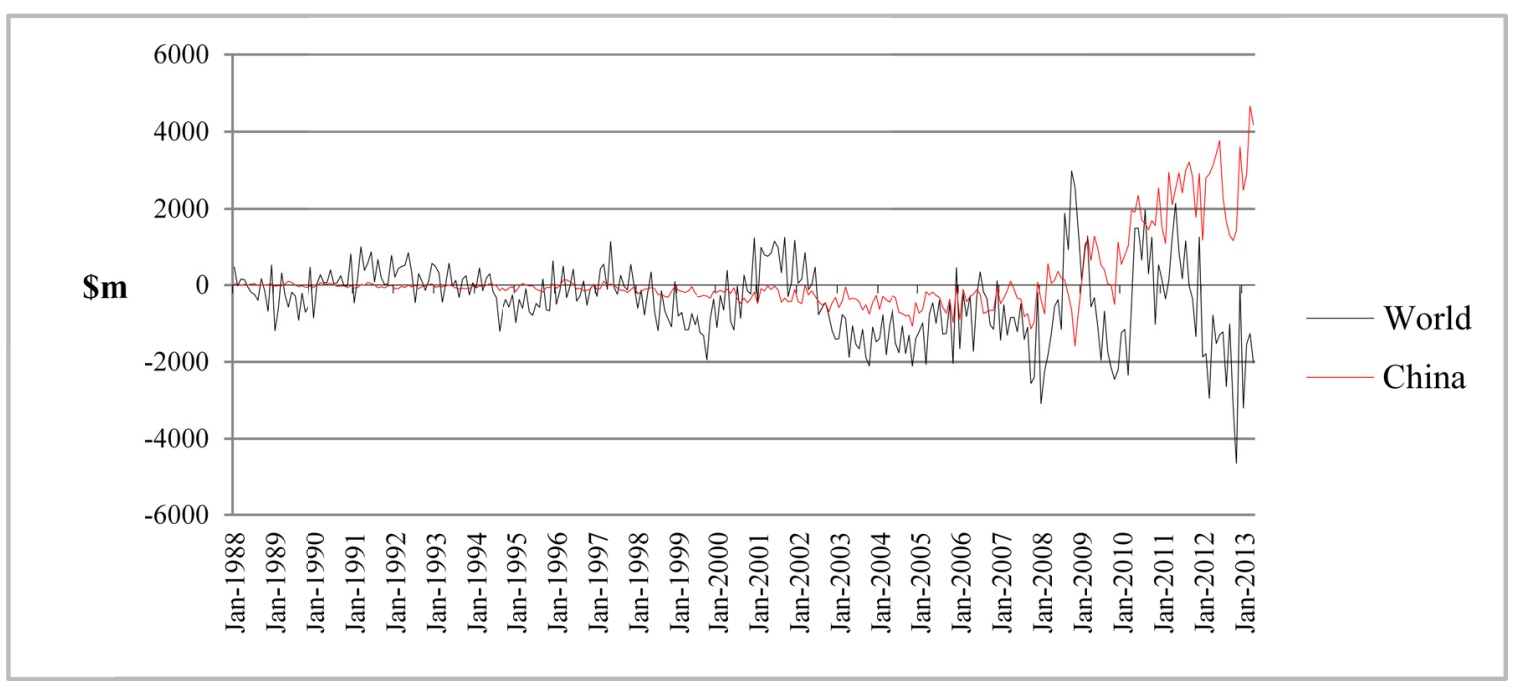

Figure 1. Australian terms of trade 1988-2013

Source: ABS Catalogue 5368014a and 5368014b.

Figure 1 shows that Australian terms of trade have strongly benefitted as a result of its trade with China, especially since the mid 2000s.

\subsection{Review of Related Literature}

Pairs trading seeks to exploit violations of the "law of one price". It identifies stocks of close economic substitutes that historically moved together over a long horizon, and buys the losers and shorts the winners when they have significantly moved apart (Do and Faff, 2011). Seasholes and Liu (2011) studies trading and prices associated with a dual-class shares by focusing on Chinese firms that list shares on both the Shanghai and Hong Kong Stock Exchanges. They find that in a frictionless world, prices should be the same across exchanges. If there are constant frictions such as a tax on one exchange, then price disparities may be constant over time. However, constant frictions could lead prices to trade within a narrow "no-arbitrage" band. In this paper the prices of Chinese Shanghai Composite (CSC) stocks and Australian resources stocks are transformed into natural logarithms and standardised. A transaction cost of $1.4 \%$ is charged based on brokerage data.

Gatev et al (2006) implement an algorithm on the US market over period 1963-2002 to test a strategy that generates a significant excess returns before trading costs. They consider the impact of the bid-ask spread, which is a proxy for market impact, and find net profit falls to 19 to 38 bps per month. Pairs trading remains profitable over the sample period of study, as well as over an out-of-sample test of four years (Gatev et al, 2006).

Englberg et al (2009) state that after pair divergence the profitability from the strategy decreases exponentially over time. A strategy which results in a closing each position within 10 days of divergence increases the average monthly return to pairs trading from $70 \mathrm{bps}$ per month to $175 \mathrm{bps}$ per month before transaction costs. The profits to a pairs trading strategy are related to news around the divergence event. They find that the profitability is related to information events that affect both returs in the pair (common shocks.. Some of the profitability can be explained by a differential response to these common information shocks. The profits to pairs trading are short-lived and directly related to information dissemination across the constituent returns of the pair. Do and Faff (2010) believed that increased competition between arbitrageurs has eventually led to increased arbitrage risk which includes both fundamental factors and trading noises. Engelberg et al (2009) look at the role of firm-specific news and common information on pairs trading returns.

Do and Faff (2011) study trading costs on pairs trading profitability in the US equity market over the period 1963-2009. After controlling for commissions, market impact and short selling fees; they find that pairs trading remains profitable. Pairs trading exhibits a lower risk .and lower return profile than a short-term reversal strategy that sorts stocks relative to their industry peers. Rather than using the distance method pioneered by Gatev et al (2009) for choosing pairs, this study uses cointegration. The idea is that if stocks pairs are cointegrated they have a long run equilibrium relationship, though in the short-run they may diverge from each other. By buying the undervalued stock and shorting the overvalued stock there will be a profit when the pairs return to their equilibrium. 
DeBondt and Thaler $(1985,1987)$ state that past losers over a long period of time, outperform past winners over a long period of time, during the subsequent three to five years. Stocks which under-perform over three to five years in the past earn higher average returns than stocks that performed well in the past. An interpretation of return predictability is that the stock market consistently overreacts to new information. The overreaction in stocks means that stock prices take temporary swings away from their fundamental values due to bouts of optimism and pessimism. Chopra, Lakonishok and Ritter (1992) state that long-term price reversals lead to investor overreaction. Jegadeesh (1990) and Lehmann (1990) provide evidence of short-term return reversals at monthly and weekly intervals. Profitability of these short-term contrarian strategies may show diminished liquidity in the market rather than overreaction. Jegadeesh and Titman (1991) demonstrate the relationship between short-term contrarian effects and bid-ask spreads. Lo and MacKinlay (1990) argue that the abnormal return reported by Jegadeesh and Titman is due to lead-lag effects in stock prices due to common factors rather than to overreaction.

Profits generated by contrarian strategies have been documented in stock markets across continents. For example, Chang, McLeavey, and Rhee (1995) show evidence of short-term abnormal returns of the contrarian investment strategy in the Japanese stock market. Campbell and Limmack (1997) show that in the 12 months following portfolio formation, loser's generated positive abnormal returns in the United Kingdom from 1979 to 1990. The very smallest loser companies experienced a reversal in their abnormal returns over the following 12 months, but that no such reversal was demonstrated for the smallest winner companies.

Baytas and Cakici (1999), find that returns to long-term contrarian strategies amongst industrialised countries are significant. They show that arbitrage portfolios based on price are greater than those based on size and outperform the winner-loser arbitrage portfolios. Zamri and Simon (2001) investigate long-run overreaction and seasonal effects for the stocks in Kuala Lumpur Stock Exchange from 1986-1996. Stock that exhibits extreme returns relative to the market over a 3 -year period experiences a reversal of fortunes during the following 3 years. A contrarian trading strategy may yield excess returns.

DeBondt and Thaler (1987) show (1) excess returns for losers are negatively related to formation period performance, while January excess returns for winners are negatively related to the excess returns for the prior December. (2) The winner-loser effect cannot be attributed to changes in risk and size effect. (3) The small firm effect is partly a losing firm effect. (4) The earnings of winning and losing firms exhibit reversal patterns that are consistent with overreaction.

Zarowin (1989) determined whether size and seasonality can account for short-run price reversals. The results indicate that losers significantly outperform winners over all months. The short-run overreaction effect is a separate anomaly. An overreaction effect that is distinct from the size effect is also found by Albert and Glenston (1995).

Chopra, Lakonishok, and Ritter (1992) find in portfolios formed on the basis of prior 5-year returns, extreme prior losers outperform extreme prior winners by $5-10 \%$ per year during the following 5 years. Overreaction is significantly more prominent amongst smaller firms than for larger firms. Returns consistent with the overreaction hypothesis are also observed for short windows around quarterly earnings announcements. Chang, McLeavey, and Rhee (1995) examines the Japanese stock market and find that: (1) a short-run contrarian strategy is profitable after systematic risk and firm size are accounted for, (2) contrarian profits are not affected by the seasonality effect, (3) abnormal profits are generated irrespective of whether losers are smaller or greater than winners (4) the size of the profits is not increased or diminished after firm size is taken into account, and (5) there is a strong nexus between the performance of the two extreme portfolios. Jegadeesh and Titman (2001) also find strong evidence of contrarian effects for small firms, and weak evidence for large firms.

\subsection{Long-Run Efficiency}

This paper proposes that contrarian strategy is a result of short-run inefficiencies, which are eliminated by arbitrage. The use of cointegartion and Markov switching means that short-run inefficiencies are eliminated as Chinese and Australian markets reach a long-run equilibrium, value which is efficient. Wilson and Marasdeh (2007) argue that cointegrating relationships between stock prices imply market efficiency in long run equilibrium. They modify the law of one price (LOOP) to the law of one vector of prices (LOVP) so that no arbitrage opportunities exist in the long run. They state that it is the presence of arbitrage activity via the cointegrating disequilibrium error correction of the real exchange rate which stabilises the system. However this process of arbitrage, which allows above average (risk adjusted) returns to be earned, means that stock markets are inefficient in the short run. Importantly this inefficient error correction adjustment continues until all 
arbitrage opportunities are eliminated. Short run stock market inefficiency ensures that stock markets are efficient in the long run.

\subsection{Partial Adjustment Model}

In this paper, Chinese and Australian stock pairs were chosen on the basis of similar speed of adjustment coefficients derived from the partial adjustment model (PAM). The PAM assumes the long-run equilibrium equation is given by the single-index model:

$$
R_{t}=a+\beta R_{m}+e
$$

Where $R_{t}$ is the target return; $a$ is the excess return; $B$ is the sensitivity of the stock to the market, $R_{m}$ is the market return; and e is the residual.

Similar to the model of Amihud and Mendelson (1987), the impact from noise trading is the difference between the fundamental return and the observed return.

The following hypothesis known as the PAM is postulated:

$$
\begin{gathered}
R_{t}-R_{t-1}=\delta\left(R_{t}-R_{t-1}\right) \\
R_{t}-R_{t-1}=\delta\left(\left(a+\beta R_{m}+e\right)-R_{t-1}\right) \\
R_{t}=\delta a+\delta \beta R_{m}+(1-\delta) R_{t-1}+\delta e \\
R_{t}=\delta a+\delta \beta R_{m}+(1-\delta) \beta R_{m t-1}+\delta e
\end{gathered}
$$

Where $R_{t}$ is the return in time period $\mathrm{t}, R_{t-1}$ is the return in time period $t-1, \delta$ is the speed of adjustment coefficient and e is the error term $\mathrm{E}[\mathrm{e}]=0$ and $\mathrm{E} \sim \mathrm{N}\left(0, \sigma^{2}\right)$. When $\delta$ equals 0 there is no adjustment, when $\delta$ equals 1 there is full adjustment and the market is efficient, when $\delta$ is greater than 1 there is an over-reaction to economic information and when $\delta$ lies between 0 and 1 there is partial adjustment or under-reaction to economic information.

There should be no opportunity to use information gathered in period t-1 to provide a correct assessment of the expected return. The information available at $\mathrm{t}-1$, the time series of past returns, should not be able to be used to correctly determine the expected return. By using past information in this way makes this approach a test of weak form market efficiency. If the variance of e is high then that would be evidence against weak form market efficiency, in addition to the value of the speed of adjustment.

The first step is to calculate the alpha (excess return) and beta (systematic risk) by regression the stock's return against the market return. The beta is multiplies by the market return and added to alpha. The proxy used for the lagged return is $\beta R_{m(t-1)}$. The stochastic explanatory variable $R_{t-1}$ may be correlated with the error term, which would make the OLS estimator biased and inconsistent so that the estimates would not approximate their true population values. This correlation can be removed by finding a suitable proxy for $R_{t-1}$. Such a proxy is $\beta R_{m(t-1)}$.

The single-index model is used in the PAM instead of a multi-factor model because the object of the PAM is to calculate the speed of adjustment coefficient. A multi-factor model would introduce too many terms in the PAM and would lead to difficulties in finding an appropriate proxy for $R_{t-1}$.

\subsection{The Law of One Price Strategy (LOP)}

The law of one price (LOP) states that once prices are converted to a common currency, the same good should sell for the same price in different countries. The empirical evidence tends not to support the hypothesis that the deviations from the LOP dampen quickly. This study proposes that the Law of One Price fails to operate in the short-run because stock pair dynamics reflects increased fundamental risks, or uncertainty in market perception of relative values of the paired securities. This leads to international arbitrage opportunities.

Caporale (2006) ran tests of PPP using the stage-three trivariate cointegration test. In its absolute form, the PPP condition states that the nominal exchange rate should be proportional to the ratio of the domestic to the foreign price level, i.e

$$
S_{t}=\alpha+\beta_{0} P_{t}-\beta_{1} P_{t}^{*}+\mu_{t}
$$

$S_{t}$ is the nominal exchange rate, $P_{t}$ is the Australian resources stock and $P_{t}^{*}$ is the CSC stock and $\mu_{t}$ stands for the regression errors. This is known as a trivariate relationship. The Engle-Granger cointegration method was implemented. The author used the following Signal Index to determine when to enter and exit a trade 


$$
R E S I D=E[\mu] \pm \delta \sigma_{\mu t}
$$

The SI is based on the $95 \%$ confidence interval, where $E\left[\mu_{t}\right]=0 \delta=1.96$. Enter the trade if the RESID (the residual) value is greater than $\delta \sigma_{\mu t}$ or less than $-\delta \sigma_{\mu t}$ standard deviations from the mean and exit the trade by reversing positions if the $+/-\delta \sigma_{\mu t}$ standard deviation is less than RESID.

When national and international markets are performing well international arbitrageurs will eliminate any mis-pricing between geographical locations. If goods and services follow the law of one price, then it is argued that the absolute level of the exchange rate should cause traded goods and services to have the same price in all countries when measured in the same currency (Appleyard et al, 2009). The stage three trivariate model tests the absolute version of purchasing price parity, which is the reason for the use of the nominal exchange rate.

The next step is to consider the LOP strategy, which is appropriate when the study focuses on international stocks. If stocks in the CSC Index and Australian resources stocks are good substitutes for each other they should be priced to the same fundamental value in efficient markets in the long-term. If one of the stocks in one index is mispriced in the short-run, rational investors will take advantage of this mis-pricing by selling the relatively overpriced one and purchasing the relatively under-priced one and earn a profit. Consequently their prices will revert to the fundamental value eventually. There should be a long-run equilibrium and the spread between them should be stationary. If they are indeed cointegrated, trading strategies, which exploit the mean reverting property of the spreads between the pairs of stocks, should result in a profit. As LOP accounts for exchange rates, it is particularly suited to pairs trading between different countries. This is a new model for pairs trading. The LOP strategy is a new statistical international arbitrage technique developed specifically for this study.

If the variables in the LOP model are found to be non-stationary, then we will apply the Engle-Granger (1987) co-integration method. This method involves estimating the long-run PPP equation by the OLS method and then recovering the residuals for cointegration tests. These residuals are tested for stationarity by applying the PP unit root tests. If these tests reveal that the residuals are stationary in their levels, then one concludes that the variables in the long-run model are cointegrated,. If the residuals are found to be non-stationary, one would then conclude that the PPP relationship does not hold. This is because, in this case, any short-run deviation from the PPP relationship will be cumulative and permanent and that the variables will not have a common trending relationship.

\subsection{Markov Switching Strategies}

The Markov switching strategy is another contrarian pairs-trading strategy. Numerous studies have applied Markov regime switching models in studying the behaviour of the stock market. The first among these studies is that of Hamilton (1989) who modelled regime shifts through the Markov switching autoregressive model.

This current study analyses pairs trading statistical international arbitrage between 33 pairs of stocks from the CSC Index and the Australian resources stocks. The pairs of stocks are selected using the speed of adjustment coefficient from the partial adjustment model. The pairs were transformed in to a relative price ratio and Markov switching models were employed.

The pairs were transformed in to a relative price ratio and Markov switching models was employed. The price ratio of two assets Australia and China are assumed to follow a mean reverting process, which implies that short-term deviations from the equilibrium ratio are balanced after a period of adjustment. The ratio exhibits a switching mean. The regime shifts are governed by a Markov chain. The current regime $\mathrm{s}_{\mathrm{t}}$ is determined by an unobservable variable. The inference of regimes is based on state probabilities. The price ratio exhibits a long-run equilibrium. Deviations from this equilibrium result in short-run international arbitrage opportunities. The ratio divides the Australian stock by the Chinese stock. If the ratio is high Australian stocks are overvalued and Chinese stocks are under-priced. The strategy would be to sell Australian stocks and simultaneously purchase Chinese stocks. If the ratio is low Australian stocks are under-priced and Chinese stocks are over-priced. The strategy would be to sell Australian stocks and purchase Chinese stocks.

The theory of pairs trading developed in this study is that there are two types of traders, noise traders and informed traders. Noise traders are irrational and uniformed traders who trade on misinformation. Informed traders are rational traders who trade on private information. Both the trades of noise traders and informed traders cause the stock pairs to diverge. Noise trader's under-react or over-react to economic news which causes the stock pairs to diverge. Informed traders trade on private information gleaned through sophisticated methodologies and analysis, which causes the stock pairs to diverge and then converge once this private information, is revealed publicly. This divergence is only transitory for Noise traders, whose divergence corrects itself and returns to the mean value. For informed traders, this divergence is more permanent, the stock pairs may 
return to the original mean or to a new mean regime.

The effects of noise traders are assumed to be captured by the LOP strategy, whilst those of informed traders are assumed to be captured by the Markov switching strategy and the issues raised are whether or not; the constituent stocks in the CSC Index and a portfolio of Australian resource stocks cointegrated; is it possible to exploit a long-run relationship between Australian resource equity prices and the CSC Index stocks by constructing trading strategies; is it possible to exploit statistical international arbitrage between stocks in the CSC Index and the Australian resource stocks; LOP or Markov switching strategies produce greater abnormal returns.

The issues raised are whether or not; the constituent stocks in the CSC Index and a portfolio of Australian resource stocks cointegrated; is it possible to exploit a long-run relationship between Australian resource equity prices and the CSC Index stocks by constructing trading strategies; is it possible to exploit statistical international arbitrage between stocks in the CSC Index and the Australian resource stocks; LOP or Markov switching strategies produce greater abnormal returns.

\section{Method}

The data is the top 33 (by market capitalisation) Australian resources stocks and CSC index and its constituent stocks from 1 January 2003 to 1 March 2013. The weekly data was obtained from Yahoo Finance. Stocks were selected based on their market capitalisation. Missing values were substituted from prices occurring the previous day. There were 532 observations. The transaction cost for Australian and Chinese trades was assumed to be 1.4\%. This was based on brokerage data from Australia and China (Hang Seng Investment October 2010; Commsec March 2013). Dividends were assumed to be reinvested.

For the LOP strategy the Engle-Granger (1987) approach was used. For the Markov switching strategy the Hamilton $(1989,1990)$ approach was used. The Australian and Chinese stocks were ranked and paired with each other based on their similar speed of adjustment coefficients. The Chinese stocks were converted to Australian dollars and transformed into logarithms. The AUD/CNY exchange rate history was acquired from the Reserve Bank of Australia.

\section{Results}

Table 1 shows the speed of adjustment coefficients for the CSC and Australian resource stocks.

Table 1. The speeds of adjustments for the CSC constituent stocks and australian resources stocks

\begin{tabular}{|c|c|c|c|c|c|c|c|}
\hline STOCK & SPEED & BETA & MCAP(mil) & STOCK & SPEED & BETA & MCAP(mil) \\
\hline 600519.ss & 1.066353 & 1.069409 & $\$ 26,386.08$ & NCM.AX & 1.563677 & 1.153444 & $\$ 14,399.05$ \\
\hline 600583.ss & 1.030761 & 1.06963 & $\$ 3,867.24$ & OGC.AX & 1.075138 & 1.194804 & $\$ 1,362.91$ \\
\hline $600050 . s s$ & 1.012694 & 0.829947 & $\$ 12,033.81$ & MDL.AX & 1.045558 & 1.066206 & $\$ 275.68$ \\
\hline 600018.SS & 1.007835 & 1.124973 & $\$ 9,494.85$ & GDO.AX & 1.041748 & 0.810438 & $\$ 339.97$ \\
\hline 600016.SS & 1.007121 & 0.581978 & $\$ 40,444.84$ & KCN.AX & 1.030601 & 0.991805 & $\$ 531.40$ \\
\hline 600879.ss & 1.005713 & 1.263689 & $\$ 1,123.44$ & AGG.AX & 1.011431 & 1.425217 & $\$ 1,831.00$ \\
\hline 600036.SS & 1.002997 & 1.290845 & $\$ 42,476.33$ & AAI.AX & 1.00767 & 0.133171 & $\$ 8,500.00$ \\
\hline 600000.SS & 1.000000 & 1.062374 & $\$ 29,108.07$ & SBM.AX & 1.007299 & 1.45542 & $\$ 514.92$ \\
\hline 600642.ss & 0.996923 & 1.110974 & $\$ 3,293.45$ & CDU.AX & 1.003231 & 0.299662 & $\$ 663.59$ \\
\hline 600037.ss & 0.996295 & 0.816957 & $\$ 1,051.03$ & RRL.AX & 1.001721 & 0.268901 & $\$ 1,878.68$ \\
\hline 600795.ss & 0.993745 & 1.15492 & $\$ 7,910.94$ & IGO.AX & 0.998803 & 0.838099 & $\$ 859.34$ \\
\hline 601600.ss & 0.992643 & 1.359832 & $\$ 7,473.80$ & SPH.AX & 0.992043 & 1.794434 & $\$ 676.63$ \\
\hline 600331.ss & 0.991439 & 1.029045 & $\$ 872.43$ & BHP.AX & 0.991112 & 0.63847 & $\$ 161,632.00$ \\
\hline 600688.ss & 0.986424 & 1.114578 & $\$ 5,543.39$ & MGX.AX & 0.989828 & 1.083146 & $\$ 512.57$ \\
\hline 600832.ss & 0.9795 & 0.829772 & $\$ 2,698.61$ & RSG.AX & 0.989793 & 1.435691 & $\$ 729.91$ \\
\hline 600028.SS & 0.979069 & 1.062374 & $\$ 104,374.24$ & IGR.AX & 0.989544 & 0.876141 & $\$ 485.90$ \\
\hline 600104.ss & 0.978776 & 0.839762 & $\$ 25,140.50$ & LYC.AX & 0.988708 & 0.996607 & $\$ 1,009.81$ \\
\hline 600887.ss & 0.978265 & 0.885271 & $\$ 8,758.22$ & SDL.AX & 0.985517 & 1.530724 & $\$ 645.14$ \\
\hline 600811.ss & 0.977933 & 1.158478 & $\$ 1,484.06$ & PNA.AX & 0.985273 & 1.334658 & $\$ 1,406.99$ \\
\hline 600100.ss & 0.973206 & 0.837848 & $\$ 2,139.77$ & ARI.AX & 0.98488 & 0.566847 & $\$ 1,020.40$ \\
\hline 600009.SS & 0.970523 & 0.996509 & $\$ 3,945.50$ & AQP.AX & 0.980083 & 0.555988 & $\$ 316.00$ \\
\hline 600011.SS & 0.96998 & 1.269564 & $\$ 14,692.24$ & BSL.AX & 0.977996 & 0.76673 & $\$ 2,651.66$ \\
\hline 600269.ss & 0.966535 & 0.892821 & $\$ 1,231.68$ & GBG.AX & 0.976579 & 0.788386 & $\$ 283.51$ \\
\hline 600005.SS & 0.965442 & 1.096068 & $\$ 4,305.68$ & TRY.AX & 0.969256 & 1.808882 & $\$ 173.96$ \\
\hline 600026.SS & 0.964137 & 0.977953 & $\$ 1,969.20$ & OZL.AX & 0.955976 & 1.33193 & $\$ 1,440.00$ \\
\hline 600111.ss & 0.959804 & 0.84184 & $\$ 10,891.46$ & SGM.AX & 0.955402 & 1.680748 & $\$ 1,936.85$ \\
\hline 600717.ss & 0.958613 & 1.128586 & $\$ 1,563.89$ & IMD.AX & 0.939148 & 0.942622 & $\$ 271.51$ \\
\hline
\end{tabular}




\begin{tabular}{cccccccc}
\hline $600177 . \mathrm{ss}$ & 0.954304 & 1.148483 & $\$ 2,676.71$ & IRN.AX & 0.93012 & 0.980166 & $\$ 409.07$ \\
$600309 . \mathrm{ss}$ & 0.949176 & 1.035379 & $\$ 6,034.06$ & EVN.AX & 0.916044 & 0.786781 & $\$ 902.82$ \\
$600362 . \mathrm{ss}$ & 0.943443 & 1.032142 & $\$ 10,341.67$ & GRR.AX & 0.897727 & 0.819006 & $\$ 219.73$ \\
$600019 . \mathrm{SS}$ & 0.942489 & 1.091093 & $\$ 12,881.11$ & RIO.AX & 0.896701 & 1.335901 & $\$ 85,933.67$ \\
$600320 . \mathrm{ss}$ & 0.93989 & 1.010157 & $\$ 1,965.18$ & SIR.AX & 0.895826 & 1.682214 & $\$ 788.42$ \\
$600601 . \mathrm{ss}$ & 0.925347 & 0.923437 & $\$ 796.68$ & WSA.AX & 0.895578 & 1.742187 & $\$ 574.78$ \\
\hline
\end{tabular}

Note: STOCK is the Chinese and Australian stock, BETA is systematic risk, MCAP is market capitalisation, SPEED is the speed of adjustment coefficient from the PAM.

Table 1 show that the 33 Australian and Chinese financial stocks are ranked in order from the fastest speed of adjustment to the slowest speed of adjustment. The fastest Chinese and Australian stocks are 600519.ss and NCM.AX, with speeds of 1.07 and 1.56, which is followed by 600583.ss and OGC.AX with speeds of 1.03 and 1.08. The slowest speeds of adjustment are 600601.ss and WSA.AX with speeds of 0.92 and 0.90 . The second slowest 9and third slowest are 600320.ss (0.94) and SIR.AX (0.90) and 600019.ss (0.94) and RIO.AX (0.90) respectively.

It may be recalled that a speed of adjustment of 1 means the stocks fully adjust to new information and that they are efficient. A speed greater than 1 means the stocks over-react and a speed of $0<\delta<1$ means the stock under-react. Remember that over-reaction leads to contrarian strategies and that under-reaction leads to momentum strategies. Thus, both contrarian and momentum strategies should be profitable in this sample.

Table 2 shows the profitability of the LOP and Markov switching strategies.

Table 2. Profitability under the LOP and Markov switching strategies

\begin{tabular}{|c|c|c|c|c|c|c|c|c|c|}
\hline STOCK & SPEED & BETA & $\operatorname{MCAP}(\mathrm{mil})$ & STOCK & SPEED & BETA & MCAP(mil) & Markov & LOP \\
\hline 600519.ss & 1.066353 & 1.069409 & $\$ 26,386.08$ & NCM.AX & 1.563677 & 1.153444 & $\$ 14,399.05$ & & \\
\hline 600583.ss & 1.030761 & 1.06963 & $\$ 3,867.24$ & OGC.AX & 1.075138 & 1.194804 & $\$ 1,362.91$ & & 0.050704 \\
\hline $600050 . \mathrm{ss}$ & 1.012694 & 0.829947 & $\$ 12,033.81$ & MDL.AX & 1.045558 & 1.066206 & $\$ 275.68$ & -0.18935 & \\
\hline 600018.SS & 1.007835 & 1.124973 & $\$ 9,494.85$ & GDO.AX & 1.041748 & 0.810438 & $\$ 339.97$ & & -0.06519 \\
\hline 600016.SS & 1.007121 & 0.581978 & $\$ 40,444.84$ & KCN.AX & 1.030601 & 0.991805 & $\$ 531.40$ & & \\
\hline $600879 . \mathrm{ss}$ & 1.005713 & 1.263689 & $\$ 1,123.44$ & AGG.AX & 1.011431 & 1.425217 & $\$ 1,831.00$ & 0.049542 & -0.01729 \\
\hline 600036.SS & 1.002997 & 1.290845 & $\$ 42,476.33$ & AAI.AX & 1.00767 & 0.133171 & $\$ 8,500.00$ & & \\
\hline 600000.SS & 1.000000 & 1.062374 & $\$ 29,108.07$ & SBM.AX & 1.007299 & 1.45542 & $\$ 514.92$ & & 0.02724 \\
\hline 600642.ss & 0.996923 & 1.110974 & $\$ 3,293.45$ & CDU.AX & 1.003231 & 0.299662 & $\$ 663.59$ & & 0.025792 \\
\hline $600037 . \mathrm{ss}$ & 0.996295 & 0.816957 & $\$ 1,051.03$ & RRL.AX & 1.001721 & 0.268901 & $\$ 1,878.68$ & & \\
\hline 600795.ss & 0.993745 & 1.15492 & $\$ 7,910.94$ & IGO.AX & 0.998803 & 0.838099 & $\$ 859.34$ & & \\
\hline $601600 . s s$ & 0.992643 & 1.359832 & $\$ 7,473.80$ & SPH.AX & 0.992043 & 1.794434 & $\$ 676.63$ & 0.021716 & -0.00137 \\
\hline 600331.ss & 0.991439 & 1.029045 & $\$ 872.43$ & BHP.AX & 0.991112 & 0.63847 & $\$ 161,632.00$ & & 0.059677 \\
\hline $600688 . \mathrm{ss}$ & 0.986424 & 1.114578 & $\$ 5,543.39$ & MGX.AX & 0.989828 & 1.083146 & $\$ 512.57$ & 0.024286 & -0.05995 \\
\hline 600832.ss & 0.9795 & 0.829772 & $\$ 2,698.61$ & RSG.AX & 0.989793 & 1.435691 & $\$ 729.91$ & & \\
\hline 600028.SS & 0.979069 & 1.062374 & $\$ 104,374.24$ & IGR.AX & 0.989544 & 0.876141 & $\$ 485.90$ & 0.116804 & \\
\hline 600104.ss & 0.978776 & 0.839762 & $\$ 25,140.50$ & LYC.AX & 0.988708 & 0.996607 & $\$ 1,009.81$ & 0.013165 & -0.03927 \\
\hline 600887.ss & 0.978265 & 0.885271 & $\$ 8,758.22$ & SDL.AX & 0.985517 & 1.530724 & $\$ 645.14$ & 0.15639 & \\
\hline 600811.ss & 0.977933 & 1.158478 & $\$ 1,484.06$ & PNA.AX & 0.985273 & 1.334658 & $\$ 1,406.99$ & & \\
\hline 600100.ss & 0.973206 & 0.837848 & $\$ 2,139.77$ & ARI.AX & 0.98488 & 0.566847 & $\$ 1,020.40$ & 0.046183 & 0.009989 \\
\hline 600009.SS & 0.970523 & 0.996509 & $\$ 3,945.50$ & AQP.AX & 0.980083 & 0.555988 & $\$ 316.00$ & & -0.01211 \\
\hline 600011.SS & 0.96998 & 1.269564 & $\$ 14,692.24$ & BSL.AX & 0.977996 & 0.76673 & $\$ 2,651.66$ & 0.079742 & \\
\hline 600269.ss & 0.966535 & 0.892821 & $\$ 1,231.68$ & GBG.AX & 0.976579 & 0.788386 & $\$ 283.51$ & & -0.04884 \\
\hline 600005.SS & 0.965442 & 1.096068 & $\$ 4,305.68$ & TRY.AX & 0.969256 & 1.808882 & $\$ 173.96$ & & 0.074548 \\
\hline 600026.SS & 0.964137 & 0.977953 & $\$ 1,969.20$ & OZL.AX & 0.955976 & 1.33193 & $\$ 1,440.00$ & 0.007575 & \\
\hline 600111.ss & 0.959804 & 0.84184 & $\$ 10,891.46$ & SGM.AX & 0.955402 & 1.680748 & $\$ 1,936.85$ & & -0.11889 \\
\hline 600717.ss & 0.958613 & 1.128586 & $\$ 1,563.89$ & IMD.AX & 0.939148 & 0.942622 & $\$ 271.51$ & 0.105597 & 0.023184 \\
\hline 600177.ss & 0.954304 & 1.148483 & $\$ 2,676.71$ & IRN.AX & 0.93012 & 0.980166 & $\$ 409.07$ & 0.097917 & -0.01317 \\
\hline 600309.ss & 0.949176 & 1.035379 & $\$ 6,034.06$ & EVN.AX & 0.916044 & 0.786781 & $\$ 902.82$ & & -0.01633 \\
\hline 600362.ss & 0.943443 & 1.032142 & $\$ 10,341.67$ & GRR.AX & 0.897727 & 0.819006 & $\$ 219.73$ & 0.136398 & \\
\hline 600019.SS & 0.942489 & 1.091093 & $\$ 12,881.11$ & RIO.AX & 0.896701 & 1.335901 & $\$ 85,933.67$ & 0.056591 & 0.073412 \\
\hline $600320 . s s$ & 0.93989 & 1.010157 & $\$ 1,965.18$ & SIR.AX & 0.895826 & 1.682214 & $\$ 788.42$ & & \\
\hline 600601.ss & 0.925347 & 0.923437 & $\$ 796.68$ & WSA.AX & 0.895578 & 1.742187 & $\$ 574.78$ & & 0.050704 \\
\hline
\end{tabular}

The STOCK is the Chinese and Australian stocks, SPEED is the speed of adjustment coefficient from the PAM, BETA is systematic risk, MCAP is market capitalisation in millions of Australian dollars. Markov is the result of the Markov strategy and LOP is the result of the LOP strategy. There were 33 Chinese and Australian stocks. The stocks were ranked in order from fastest speed of adjustments to slowest speed of adjustments. LOP is the outcome of the LOP strategy and Markov is the outcome of the Markov switching strategy. 
The Table 2 shows that the LOP strategy largest returns were 5.1\% (OGC/600583), 6\% (BHP/600331), 7.5\% (TRY/600005) and 7.3\% (RIO/600019) annually. This strategy captured temporary divergences from the mean only later to return to their long-run equilibrium value. This strategy captured the influence of noise traders. Noise traders are supposed to be retail investors who trade in small caps. The Table 2 shows that the Markov strategy had the largest returns of 19\% (MDL/600050), 12\% (IGR/600028), 16\% (SDL/600887) and 14\% (GRR/600362) annually.

The Markov strategy captures permanent changes in pairs-trading. It is believed that informed traders are more likely to make permanent changes than noise traders (who make transitory changes). The largest cap pairs were not cointegrated under the LOP strategy nor did they have regime-switching characteristics. It is surmised that very large cap stocks are followed by many analysts and trade close to their fundamentals and so offer few arbitrage opportunities.

Small cap stock pairs are generally more profitable than large cap stock pairs, perhaps reflecting the fact that they are riskier and thus require a higher rate of return. Generally, informed traders are more profitable than noise traders. The CSC constituent stocks and the Australian resources stocks are cointegrated and two successful pairs-trading strategies were implemented. The Markov switching strategy was more profitable, demonstrating that informed traders are more profitable in their trades than noise traders.

Figure 2 shows the efficient frontier for the LOP and Markov switching strategies.

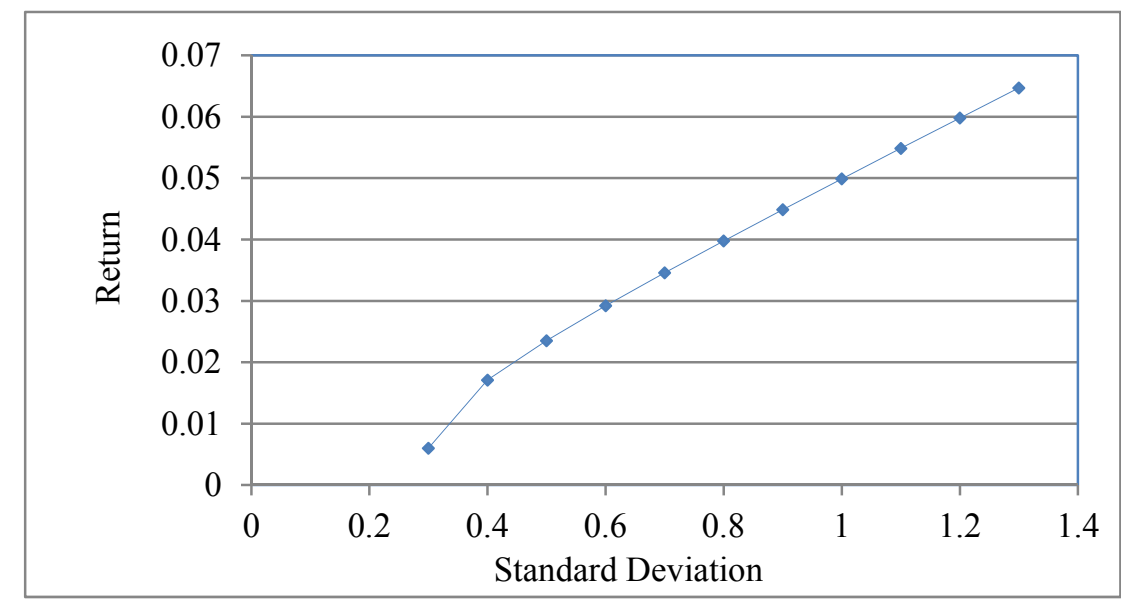

Figure 2. The efficient frontier for LOP and Markov switching strategies

The Sharpe ratio was maximised $(20 \%)$ to find the optimal portfolio. It was determined that the portfolio consisted of going long in the LOP portfolio (91.7\%) and the Markov portfolio (8.3\%) for a return of $0.4 \%$.

Table 3 shows the results for the test of the lead-lag relationships.

Table 3. Lead-lag effects in the LOP strategy

\begin{tabular}{ccccccccc}
\hline STOCK & SPEED & BETA & MCAP(mil) & STOCK & SPEED & BETA & MCAP(mil) & LOP \\
\hline $600601 . s s$ & 0.925347 & 0.923437 & $\$ 796.68$ & NCM.AX & 1.563677 & 1.153444 & $\$ 14,399.05$ & $\mathbf{- 0 . 0 3 2 4 7}$ \\
$600320 . \mathrm{ss}$ & 0.93989 & 1.010157 & $\$ 1,965.18$ & OGC.AX & 1.075138 & 1.194804 & $\$ 1,362.91$ & $\mathbf{0 . 0 5 2 1 3 5}$ \\
$600019 . \mathrm{SS}$ & 0.942489 & 1.091093 & $\$ 12,881.11$ & MDL.AX & 1.045558 & 1.066206 & $\$ 275.68$ & $\mathbf{- 0 . 0 2 4 1 1}$ \\
$600362 . \mathrm{ss}$ & 0.943443 & 1.032142 & $\$ 10,341.67$ & GDO.AX & 1.041748 & 0.810438 & $\$ 339.97$ & $\mathbf{- 0 . 1 5 4 7 5}$ \\
$600177 . \mathrm{ss}$ & 0.954304 & 1.148483 & $\$ 2,676.71$ & AGG.AX & 1.011431 & 1.425217 & $\$ 1,831.00$ & $\mathbf{0 . 0 2 8 3 9 3}$ \\
$600717 . \mathrm{ss}$ & 0.958613 & 1.128586 & $\$ 1,563.89$ & AAI.AX & 1.00767 & 0.133171 & $\$ 8,500.00$ & $\mathbf{- 0 . 0 3 2 2 3}$ \\
$600111 . \mathrm{ss}$ & 0.959804 & 0.84184 & $\$ 10,891.46$ & SBM.AX & 1.007299 & 1.45542 & $\$ 514.92$ & $\mathbf{- 0 . 0 8 3 5 3}$ \\
$600026 . \mathrm{SS}$ & 0.964137 & 0.977953 & $\$ 1,969.20$ & CDU.AX & 1.003231 & 0.299662 & $\$ 663.59$ & $\mathbf{- 0 . 0 0 7 2 2}$ \\
$600005 . \mathrm{SS}$ & 0.965442 & 1.096068 & $\$ 4,305.68$ & RRL.AX & 1.001721 & 0.268901 & $\$ 1,878.68$ & $\mathbf{- 0 . 0 5 0 9 1}$ \\
$600269 . \mathrm{ss}$ & 0.966535 & 0.892821 & $\$ 1,231.68$ & IGO.AX & 0.998803 & 0.838099 & $\$ 859.34$ & $\mathbf{0 . 0 5 5 9 3 3}$ \\
$600011 . S S$ & 0.96998 & 1.269564 & $\$ 14,692.24$ & SPH.AX & 0.992043 & 1.794434 & $\$ 676.63$ & $\mathbf{- 0 . 0 2 3 7 7}$ \\
$600009 . \mathrm{SS}$ & 0.970523 & 0.996509 & $\$ 3,945.50$ & BHP.AX & 0.991112 & 0.63847 & $\$ 161,632.00$ & $\mathbf{0 . 0 2 4 4 9 9}$ \\
$600100 . \mathrm{ss}$ & 0.973206 & 0.837848 & $\$ 2,139.77$ & MGX.AX & 0.989828 & 1.083146 & $\$ 512.57$ & $\mathbf{- 0 . 1 0 6 1 6}$ \\
$600811 . \mathrm{ss}$ & 0.977933 & 1.158478 & $\$ 1,484.06$ & RSG.AX & 0.989793 & 1.435691 & $\$ 729.91$ & $\mathbf{- 0 . 0 6 5 0 2}$ \\
\hline
\end{tabular}




\begin{tabular}{ccccccccc}
\hline $600887 . \mathrm{ss}$ & 0.978265 & 0.885271 & $\$ 8,758.22$ & IGR.AX & 0.989544 & 0.876141 & $\$ 485.90$ & $\mathbf{- 0 . 0 0 9 9 1}$ \\
$600104 . \mathrm{ss}$ & 0.978776 & 0.839762 & $\$ 25,140.50$ & LYC.AX & 0.988708 & 0.996607 & $\$ 1,009.81$ & $\mathbf{- 0 . 0 8 8 1 1}$ \\
$600028 . \mathrm{SS}$ & 0.979069 & 1.062374 & $\$ 104,374.24$ & SDL.AX & 0.985517 & 1.530724 & $\$ 645.14$ & $\mathbf{- 0 . 0 1 5 2 4}$ \\
$600832 . \mathrm{ss}$ & 0.9795 & 0.829772 & $\$ 2,698.61$ & PNA.AX & 0.985273 & 1.334658 & $\$ 1,406.99$ & $\mathbf{- 0 . 0 5 4 9 8}$ \\
$600688 . \mathrm{ss}$ & 0.986424 & 1.114578 & $\$ 5,543.39$ & ARI.AX & 0.98488 & 0.566847 & $\$ 1,020.40$ & $\mathbf{- 0 . 0 7 0 1 2}$ \\
$600331 . \mathrm{ss}$ & 0.991439 & 1.029045 & $\$ 872.43$ & AQP.AX & 0.980083 & 0.555988 & $\$ 316.00$ & $\mathbf{- 0 . 0 4 6 7}$ \\
$601600 . \mathrm{ss}$ & 0.992643 & 1.359832 & $\$ 7,473.80$ & BSL.AX & 0.977996 & 0.76673 & $\$ 2,651.66$ & $\mathbf{- 0 . 0 8 9 2 7}$ \\
$600795 . \mathrm{ss}$ & 0.993745 & 1.15492 & $\$ 7,910.94$ & GBG.AX & 0.976579 & 0.788386 & $\$ 283.51$ & $\mathbf{0 . 0 2 6 1 4}$ \\
$600037 . \mathrm{ss}$ & 0.996295 & 0.816957 & $\$ 1,051.03$ & TRY.AX & 0.969256 & 1.808882 & $\$ 173.96$ & $\mathbf{0 . 0 0 2 3 8 3}$ \\
$600642 . \mathrm{ss}$ & 0.996923 & 1.110974 & $\$ 3,293.45$ & OZL.AX & 0.955976 & 1.33193 & $\$ 1,440.00$ & $\mathbf{- 0 . 0 2 3 1}$ \\
$600000 . \mathrm{SS}$ & 1.000000 & 1.062374 & $\$ 29,108.07$ & SGM.AX & 0.955402 & 1.680748 & $\$ 1,936.85$ & $\mathbf{- 0 . 0 6 7 4 5}$ \\
$600036 . \mathrm{SS}$ & 1.002997 & 1.290845 & $\$ 42,476.33$ & IMD.AX & 0.939148 & 0.942622 & $\$ 271.51$ & $\mathbf{0 . 0 4 6 3 7 1}$ \\
$600879 . \mathrm{ss}$ & 1.005713 & 1.263689 & $\$ 1,123.44$ & IRN.AX & 0.93012 & 0.980166 & $\$ 409.07$ & $\mathbf{- 0 . 0 7 0 6 6}$ \\
$600016 . \mathrm{SS}$ & 1.007121 & 0.581978 & $\$ 40,444.84$ & EVN.AX & 0.916044 & 0.786781 & $\$ 902.82$ & $\mathbf{0 . 0 5 8 8 5 8}$ \\
$600018 . \mathrm{SS}$ & 1.007835 & 1.124973 & $\$ 9,494.85$ & GRR.AX & 0.897727 & 0.819006 & $\$ 219.73$ & $\mathbf{- 0 . 0 0 4 0 2}$ \\
$600050 . \mathrm{ss}$ & 1.012694 & 0.829947 & $\$ 12,033.81$ & RIO.AX & 0.896701 & 1.335901 & $\$ 85,933.67$ & $\mathbf{0 . 1 0 0 3 9 6}$ \\
$600583 . \mathrm{ss}$ & 1.030761 & 1.06963 & $\$ 3,867.24$ & SIR.AX & 0.895826 & 1.682214 & $\$ 788.42$ & $\mathbf{- 0 . 1 0 5 0 5}$ \\
$600519 . \mathrm{ss}$ & 1.066353 & 1.069409 & $\$ 26,386.08$ & WSA.AX & 0.895578 & 1.742187 & $\$ 574.78$ & $\mathbf{- 0 . 0 4 9 9 4}$ \\
\hline
\end{tabular}

The STOCK is the Chinese and Australian stocks, SPEED is the speed of adjustment coefficient from the PAM, BETA is systematic risk, MCAP is market capitalisation in millions of Australian dollars. There were 33 Chinese and Australian stocks. The stocks were ranked in order from fastest speed of adjustments to slowest speed of adjustments. LOP is the outcome of the LOP strategy

Lead-lag effects are constructed by combining Chinese and Australian stocks with faster speed of adjustments to stocks with those with slower speeds of adjustments. The results of Table 3 show that most of the portfolios are not profitable using lead-lag effects. There are only small profits to be made from the other stock pairs.

\section{Conclusion}

The study shows that international contrarian strategies are profitable between China and Australia, with Markov switching strategies being more profitable than LOP strategies. Chinese and Australian resource stocks were cointegrated and showed regime switching characteristics. The study lends qualified support to DeBondt and Thaler, Jegadeesh and others who advocate the over-reaction hypotheses. It is qualified because stocks which under-react was also profitable under the contrarian strategy tested. It is surmised that the reason for this puzzle is that the contrarian strategies used in this paper is a pairs-trading strategy using cointegration, the stocks which under-react and over-react represents divergences from equilibrium, and provide profitable trading opportunities by shorting the higher priced stock and going long in the under-priced stock and closing the position once the stock pairs converge on their long-run equilibrium value. Support is provided to Wilson and Marahsdeh in that the cointegrating relationship represents a long-run equilibrium in which the stocks are efficient. In the short-run there is inefficiency which results in arbitrage opportunities. Small cap stocks were generally more profitable than large cap stocks. Therefore the size-effect hypothesis is supported. The size-effect is distinct from the over-reaction effect. Lead-lag effects do not seem to explain contrarian effects in this study.

\section{Acknowledgements}

Santosh Mon Abraham is supported by a Curtin University Postgraduate Scholarship and Curtin Research Scholarship. He would like to thank Adjunct Professor John Simpson for his comments and suggestions.

\section{References}

Albert, R. L., \& Henderson, G. V. (1995). Firm size, overreaction and return reversals. Quarterly Journal of Business and Economics, 34, 60-81.

Appleyard, D. R., Field, A. J., \& Cobb, L. (2010). International economics (7th ed.). Boston: McGraw-Hill Irwin.

Ball, R., \& Kothari, S. (1995). Problems in measuring portfolio performance: An application to contrarian investment strategies. Journal of Financial Economics, 38, $79-107$. http://dx.doi.org/10.1016/0304-405X(94)00806-C

Baytas, A., \& Cakici, N. (1999). Do markets overreact: International evidence. Journal of Banking and Finance, 23, 1121-1144. http://dx.doi.org/10.1016/S0378-4266(98)00133-2

Campell, K., \& Limmack, R. J. (1997). Long-term over-reaction in the UK stock market and size adjustments. Applied Financial Economics, 5, 537-549. http://dx.doi.org/10.1080/096031097333402 
Caporale, G. M., \& Hanck, C. (2006). Cointegration tests of PPP: Do they also exhibit erratic behaviour? CESifo working dissertation, No. 1811.

Chan, L. K., Jegadeesh, N., \& Lakonishok, J. (1996). Momentum strategies. Journal of Finance, 51, 1681-1713. http://dx.doi.org/10.1111/j.1540-6261.1996.tb05222.x

Chang, R. P., McLeavey, D. W., \& Rhee, S. G. (1995). Short-term abnormal returns of the contrarian strategy in the Japanese stock market. Journal of Business Finance \& Accounting, 22, 1035-1049. http://dx.doi.org/10.1111/j.1468-5957.1995.tb00892.x

Chopra, N., Lakonishok, J., \& Ritter, J. R. (1992). Measuring abnormal performance: Do stocks overreact? Journal of Financial Economics, 31, 235-269. http://dx.doi.org/10.1016/0304-405X(92)90005-I

De Bondt, W. F. M., \& Thaler, R. H. (1985). Does the stock market overreact? Journal of Finance, 40, 793-805. http://dx.doi.org/10.1111/j.1540-6261.1985.tb05004.x

De Bondt, W. F. M., \& Thaler, R. H. (1987). Further evidence of investor overreaction and stock market seasonality. Journal of Finance, 42, 557-581. http://dx.doi.org/10.1111/j.1540-6261.1987.tb04569.x

Do, B., \& Faff, R. (2010). Does simple pairs trading still work? Financial Analysts Journal, 66(4), 83-95. http://dx.doi.org/ 10.2469/faj.v66.n4.1

Do, B., \& Faff, R. (2011). Are pairs trading profits robust to trading costs? Journal of Financial Research, 35, 261-287. http://dx.doi.org/10.1111/j.1475-6803.2012.01317.x

Engelberg, J., Gao, P., \& Jagannathan, R. (2009). An anatomy of pairs trading: The role of idiosyncratic news, common information and liquidity. http://dx.doi.org/10.2139/ssrn.1330689

Engle, R., \& Granger, C. (1987). Co-integration and error correction: Representation, estimation, and testing. Econometrica, 55(2), 251-276. http://dx.doi.org/10.2307/1913236

Gatev, E., Goetzmann, W. N., \& Rouwenhorst, K. G. (2006). Pairs trading: Performance of a relative value arbitrage rule. Review of Financial Studies, 19, 797-827. http://dx.doi.org/10.1093/rfs/hhj020

Hamilton, J. D. (1989). A new approach to the economic analysis of nonstationary time series and the business cycle. Econometrica, 57, 357-84. http://dx.doi.org/10.2307/1912559

Jegadeesh, N. (1990). Evidence of predictable behaviour of security returns. Journal of Finance, 45, 881-899. http://dx.doi.org/10.1111/j.1540-6261.1990.tb05110.x

Jegadeesh, N., \& Titman, S. (1991). Short horizon return reversals and the bid-ask spread. Working paper, University of California at Los Angeles.

Jegadeesh, N., \& Titman, S. (1993). Returns to buying winners and selling losers: Implications from stock market efficiency. Journal of Finance, 48, 65-91. http://dx.doi.org/10.1111/j.1540-6261.1993.tb04702.x

Jegadeesh, N., \& Titman, S. (2001). Profitability of momentum strategies: An evaluation of alternative explanations. The Journal of Finance, 56, 699-720. http://dx.doi.org/10.1111/0022-1082.00342

Lehmann, B. N. (1990). Fads, martingales, and market efficiency. Quarterly Journal of Economics, 105, 1-28. http://dx.doi.org/ 10.2307/2937816

Lo, A. W., \& MacKinlay, A. C. (1990). When are contrarian profits due to stock market over reaction? Review of Financial Studies, 3, 175-208. http://dx.doi.org/10.1093/rfs/3.2.175

Seasholes, M. S., \& Liu, C. (2011). Trading imbalances and the law of one price. Economics Letters, 112, 132 134. http://dx.doi.org/10.1016/j.econlet.2011.03.017

Wilson, E. J., \& Marashdeh, H. A. (2007). Are co-integrated stock prices consistent with the efficient market hypothesis? The Economic Record, 83(1), 87-93. http://dx.doi.org/10.1111/j.1475-4932.2007.00409.x

Zamri, A., \& Simon, H. (2001). KLSE long run overreaction and the Chinese new year effect. Journal of Business Finance \& Accounting, 22(28), 63-105. http://dx.doi.org/10.1016/0304-405x(94)00806-c

Zarowin, P. (1989). Short run market over reaction: Size and seasonality effects. Journal of Portfolio Management, 15, 26. http://dx.doi.org/10.3905/jpm.1989.409209 


\section{Appendix}

Appendix A shows the Phillips-Perron unit root tests for all variables in levels and first differences.

Appendix A. The results of the Phillips-Perron unit root test diagnostics for the LOP strategy

\begin{tabular}{|c|c|c|c|c|c|}
\hline Stock & Levels & First Differences & Stock & Levels & First Differences \\
\hline 600028.SS & -2.030492 & -18.1853 & BHP.AX & -1.789949 & -19.4243 \\
\hline 600036.SS & -1.783776 & -20.07855 & RIO.AX & -0.72826 & -20.93433 \\
\hline 600016.SS & -1.697201 & -20.7515 & NCM.AX & -0.669432 & -22.78356 \\
\hline 600000.SS & -1.015668 & -18.93357 & AAI.AX & -1.052124 & -18.58073 \\
\hline 600519.ss & -2.092865 & -19.11719 & BSL.AX & 1.223907 & -19.4238 \\
\hline 600104.ss & -1.409045 & -17.80774 & SGM.AX & -1.169613 & -17.63204 \\
\hline 600011.SS & -2.473115 & -19.90742 & RRL.AX & -2.173183 & -19.88612 \\
\hline 600019.SS & -2.112101 & -18.69115 & AGG.AX & -1.675569 & -19.58296 \\
\hline 600050.ss & -1.720994 & -18.65704 & OZL.AX & -2.49902 & -18.6707 \\
\hline 600111.ss & 0.591360 & -16.99201 & PNA.AX & -0.607648 & -21.84064 \\
\hline 600362.ss & -1.652565 & -18.1664 & OGC.AX & -1.292835 & -20.57792 \\
\hline 600018.SS & -1.630147 & -16.73679 & ARI.AX & -1.51602 & -18.91468 \\
\hline 600887.ss & -1.100041 & -18.5426 & LYC.AX & -1.237187 & -22.61299 \\
\hline 600795.ss & -1.477894 & -19.97876 & EVN.AX & -1.425457 & -21.04726 \\
\hline 601600.ss & -1.429288 & -17.02659 & IGO.AX & -1.820467 & -21.80357 \\
\hline 600309.ss & -2.162988 & -19.84556 & SIR.AX & -1.991451 & -18.23804 \\
\hline 600688.ss & -2.287396 & -18.08183 & RSG.AX & -1.236536 & -20.70854 \\
\hline 600005.SS & -2.184847 & -20.05749 & SPH.AX & -1.768171 & -19.82232 \\
\hline 600009.SS & -2.554252 & -16.4983 & CDU.AX & -2.514544 & -19.26155 \\
\hline 600583.ss & -1.836717 & -20.11443 & SDL.AX & 0.403509 & -22.6629 \\
\hline 600642.ss & -2.197672 & -19.96942 & WSA.AX & -2.36573 & -19.55769 \\
\hline 600832.ss & -1.947286 & -16.3328 & KCN.AX & -1.202095 & -22.47076 \\
\hline 600177.ss & -1.942872 & -17.34149 & SBM.AX & -0.662528 & -21.66665 \\
\hline 600100.ss & -0.98052 & -18.1559 & MGX.AX & -1.669223 & -18.60804 \\
\hline 600026.SS & -1.572603 & -17.63316 & IGR.AX & 0.132306 & -22.08376 \\
\hline $600320 . s s$ & -2.545069 & -19.28504 & IRN.AX & -2.494256 & -20.80207 \\
\hline 600717.ss & -2.165044 & -18.50141 & GDO.AX & -0.854242 & -20.98874 \\
\hline 600811.ss & -1.353866 & -17.03997 & AQP.AX & -1.276417 & -17.60174 \\
\hline 600269.ss & -1.761809 & -20.14715 & GBG.AX & -1.453913 & -20.91228 \\
\hline 600879.ss & -2.412794 & -18.13257 & MDL.AX & 0.044004 & -19.81493 \\
\hline 600037.ss & -1.627832 & -17.90741 & IMD.AX & -1.231399 & -20.09475 \\
\hline 600331.ss & -1.988705 & -16.45941 & GRR.AX & -2.468325 & -17.58637 \\
\hline 600601.ss & -1.965827 & -18.60042 & TRY.AX & -3.314246 & -15.63189 \\
\hline
\end{tabular}

Note: The critical values are $-3.442460(1 \%) ;-2.866774(5 \%) ;-2.569618(10 \%)$.

The results of the PP unit root tests show that the variables are non-stationary in levels and stationary after first differences.

Appendix B shows the diagnostics for the PAM.

Appendix B. The diagnostics of the Partial Adjustment Model

\begin{tabular}{|c|c|c|c|c|c|c|c|c|c|}
\hline STOCK & COEFF & $\mathrm{t}$-Stat & R-SQR & DW & STOCK & COEFF & $\mathrm{t}-\mathrm{Stat}$ & R-SQR & DW \\
\hline 600519.ss & -0.06635 & -1.44072 & 0.032405 & 2.546665 & NCM.AX & -0.56368 & -6.68554 & 0.016583 & 2.426353 \\
\hline 600583.ss & -0.03076 & -1.02931 & 0.044919 & 2.079458 & OGC.AX & -0.07514 & -1.75907 & 0.001275 & 1.990348 \\
\hline $600050 . s s$ & -0.01269 & -0.8975 & 0.235009 & 1.994056 & MDL.AX & -0.04556 & -0.50602 & 0.000107 & 1.983126 \\
\hline 600018.SS & -0.00784 & -0.26498 & 0.049202 & 1.933736 & GDO.AX & -0.04175 & -0.10994 & 0.03068 & 1.436451 \\
\hline 600016.SS & -0.00712 & -0.4774 & 0.355705 & 1.986318 & KCN.AX & -0.0306 & -0.66951 & 0.000281 & 1.975596 \\
\hline 600879.ss & 0.021735 & 1.057289 & 0.092408 & 1.945672 & AGG.AX & -0.01143 & -0.7894 & 0.000245 & 2.262396 \\
\hline 600036.SS & -0.003 & -0.24223 & 0.462789 & 2.052398 & AAI.AX & -0.00767 & -0.51201 & 0.002521 & 2.108659 \\
\hline 600000.SS & $-3.21 \mathrm{E}-17$ & -0.79028 & 1 & 1.981371 & SBM.AX & -0.0073 & -0.13522 & 0.002402 & 2.442574 \\
\hline 600642.ss & 0.013576 & 0.825776 & 0.150931 & 1.974525 & CDU.AX & -0.00323 & -0.07279 & 0.000717 & 1.983054 \\
\hline 600037.ss & 0.003705 & 0.193506 & 0.112075 & 1.929668 & RRL.AX & -0.00172 & -0.05083 & 0.001636 & 2.023806 \\
\hline 600795.ss & 0.022067 & 2.170131 & 0.445671 & 1.954692 & IGO.AX & 0.001197 & 0.038107 & 0.002755 & 2.045536 \\
\hline 601600.ss & 0.074653 & 4.453399 & 0.145518 & 1.925693 & SPH.AX & 0.007957 & 0.203515 & 0.000298 & 2.137731 \\
\hline 600331.ss & 0.008561 & 0.344598 & 0.059474 & 1.961403 & BHP.AX & 0.008888 & 0.914902 & 0.016881 & 2.092183 \\
\hline 600688.ss & 0.041387 & 2.283704 & 0.125279 & 1.80875 & MGX.AX & 0.010172 & 0.476272 & 0.005139 & 2.000023 \\
\hline 600832.ss & -0.00571 & -0.28819 & 0.090846 & 1.980106 & RSG.AX & 0.010207 & 0.278675 & 0.000342 & 2.02444 \\
\hline 600028.SS & 0.020931 & 1.5681 & 0.249952 & 1.987171 & IGR.AX & 0.010456 & 0.219221 & 0.002899 & 2.213796 \\
\hline 600104.ss & 0.021224 & 1.219567 & 0.14363 & 1.963668 & LYC.AX & 0.011292 & 0.403605 & 0.004726 & 2.129354 \\
\hline 600887.ss & 0.007357 & 0.280681 & 0.071196 & 1.916792 & SDL.AX & 0.014483 & 0.313774 & 0.000354 & 1.998599 \\
\hline 600811.ss & 0.0205 & 1.320724 & 0.17357 & 1.896156 & PNA.AX & 0.014727 & 0.50289 & 0.001281 & 2.005987 \\
\hline
\end{tabular}




\begin{tabular}{lccccccccc}
\hline $600100 . \mathrm{ss}$ & 0.026794 & 1.368446 & 0.099737 & 2.011594 & ARI.AX & 0.01512 & 0.899238 & 0.008397 & 2.108659 \\
$600009 . \mathrm{SS}$ & 0.029477 & 1.679053 & 0.177301 & 1.919847 & AQP.AX & 0.019917 & 1.183306 & 0.016273 & 1.945965 \\
$600011 . \mathrm{SS}$ & 0.03002 & 1.716363 & 0.130375 & 1.918208 & BSL.AX & 0.022004 & 0.903593 & 0.001078 & 1.960833 \\
$600269 . \mathrm{ss}$ & 0.033465 & 2.489689 & 0.027937 & 1.917883 & GBG.AX & 0.023421 & 0.927618 & 0.006369 & 2.132077 \\
$600005 . \mathrm{SS}$ & 0.034558 & 2.030829 & 0.171972 & 1.927024 & TRY.AX & 0.030744 & 1.726071 & 0.006125 & 1.947409 \\
$600026 . \mathrm{SS}$ & 0.035863 & 2.704828 & 0.239411 & 1.914828 & OZL.AX & 0.044024 & 1.962422 & 0.013189 & 2.066952 \\
$600111 . \mathrm{ss}$ & 0.040196 & 1.806807 & 0.076551 & 2.057708 & SGM.AX & 0.044598 & 0.355612 & 0.002634 & 2.07253 \\
$600717 . \mathrm{ss}$ & 0.006255 & 0.30894 & 0.129601 & 2.049608 & IMD.AX & 0.060852 & 2.052789 & 0.006355 & 1.995376 \\
$600177 . \mathrm{ss}$ & 0.045696 & 2.542071 & 0.166572 & 2.003923 & IRN.AX & 0.06988 & 1.460731 & 0.00259 & 2.126806 \\
$600309 . \mathrm{ss}$ & 0.050824 & 2.476643 & 0.106353 & 1.924252 & EVN.AX & 0.083956 & 2.025263 & 0.002926 & 2.155215 \\
$600362 . \mathrm{ss}$ & 0.056557 & 3.709431 & 0.162702 & 1.931578 & GRR.AX & 0.102273 & 2.419297 & 0.006435 & 1.96512 \\
$600019 . \mathrm{SS}$ & 0.057511 & 4.229059 & 0.261901 & 1.919321 & RIO.AX & 0.103299 & 1.374927 & 0.002429 & 2.10072 \\
$600320 . \mathrm{ss}$ & 0.06011 & 2.597692 & 0.084937 & 2.068515 & SIR.AX & 0.104174 & 2.051616 & 0.003681 & 2.044306 \\
$600601 . \mathrm{ss}$ & 0.003077 & 0.170727 & 0.123513 & 2.011847 & WSA.AX & 0.104422 & 0.556284 & 0.000178 & 2.135877 \\
\hline
\end{tabular}

Note: COEFF means coefficient; t-Stat means t-statistic; R-SQR means R2 coefficient; DW means Durbin-Watson.

The Table 5 shows that the results were not significant for the following stocks: $600019 ; 600026 ; 600177$; 600269; 600309; 600320; 600362; 600688; 600795; 601600; EVN.AX; GRR.AX; IMD.AX; NCM.AX; OZL.AX; SIR.AX.

Appendix C shows the error correction term for the LOP residuals.

Appendix C. The error correction term for the LOP residuals

\begin{tabular}{cccccccccc}
\hline STOCK & SPEED & BETA & MCAP(mil) & STOCK & SPEED & BETA & MCAP(mil) & AVGSPD & ABS \\
\hline $600583 . \mathrm{ss}$ & 1.030761 & 1.06963 & $\$ 3,867.24$ & OGC.AX & 1.075138 & 1.194804 & $\$ 1,362.91$ & -0.00263 & $\mathbf{0 . 0 0 2 6 3 4}$ \\
$600018 . \mathrm{SS}$ & 1.007835 & 1.124973 & $\$ 9,494.85$ & GDO.AX & 1.041748 & 0.810438 & $\$ 339.97$ & -0.00243 & $\mathbf{0 . 0 0 2 4 2 9}$ \\
$600879 . \mathrm{ss}$ & 1.005713 & 1.263689 & $\$ 1,123.44$ & AGG.AX & 1.011431 & 1.425217 & $\$ 1,831.00$ & -0.02079 & $\mathbf{0 . 0 2 0 7 9 3}$ \\
$600000 . \mathrm{SS}$ & 1.000000 & 1.062374 & $\$ 29,108.07$ & SBM.AX & 1.007299 & 1.45542 & $\$ 514.92$ & -0.00672 & $\mathbf{0 . 0 0 6 7 1 9}$ \\
$600642 . \mathrm{ss}$ & 0.996923 & 1.110974 & $\$ 3,293.45$ & CDU.AX & 1.003231 & 0.299662 & $\$ 663.59$ & -0.00038 & $\mathbf{0 . 0 0 0 3 7 9}$ \\
$601600 . \mathrm{ss}$ & 0.992643 & 1.359832 & $\$ 7,473.80$ & SPH.AX & 0.992043 & 1.794434 & $\$ 676.63$ & -0.00337 & $\mathbf{0 . 0 0 3 3 6 7}$ \\
$600331 . \mathrm{ss}$ & 0.991439 & 1.029045 & $\$ 872.43$ & BHP.AX & 0.991112 & 0.63847 & $\$ 161,632.00$ & -0.01469 & $\mathbf{0 . 0 1 4 6 9}$ \\
$600688 . \mathrm{ss}$ & 0.986424 & 1.114578 & $\$ 5,543.39$ & MGX.AX & 0.989828 & 1.083146 & $\$ 512.57$ & -0.00674 & $\mathbf{0 . 0 0 6 7 4 1}$ \\
$600104 . \mathrm{ss}$ & 0.978776 & 0.839762 & $\$ 25,140.50$ & LYC.AX & 0.988708 & 0.996607 & $\$ 1,009.81$ & -0.00902 & $\mathbf{0 . 0 0 9 0 2}$ \\
$600100 . \mathrm{ss}$ & 0.973206 & 0.837848 & $\$ 2,139.77$ & ARI.AX & 0.98488 & 0.566847 & $\$ 1,020.40$ & 0.000363 & $\mathbf{0 . 0 0 0 3 6 3}$ \\
$600009 . \mathrm{SS}$ & 0.970523 & 0.996509 & $\$ 3,945.50$ & AQP.AX & 0.980083 & 0.555988 & $\$ 316.00$ & 0.002064 & $\mathbf{0 . 0 0 2 0 6 4}$ \\
$600269 . \mathrm{ss}$ & 0.966535 & 0.892821 & $\$ 1,231.68$ & GBG.AX & 0.976579 & 0.788386 & $\$ 283.51$ & -0.0005 & $\mathbf{0 . 0 0 0 5 0 4}$ \\
$600005 . \mathrm{SS}$ & 0.965442 & 1.096068 & $\$ 4,305.68$ & TRY.AX & 0.969256 & 1.808882 & $\$ 173.96$ & 0.000218 & $\mathbf{0 . 0 0 0 2 1 8}$ \\
$600111 . \mathrm{ss}$ & 0.959804 & 0.84184 & $\$ 10,891.46$ & SGM.AX & 0.955402 & 1.680748 & $\$ 1,936.85$ & -0.00239 & $\mathbf{0 . 0 0 2 3 8 9}$ \\
$600717 . \mathrm{ss}$ & 0.958613 & 1.128586 & $\$ 1,563.89$ & IMD.AX & 0.939148 & 0.942622 & $\$ 271.51$ & -0.00127 & $\mathbf{0 . 0 0 1 2 6 6}$ \\
$600177 . \mathrm{ss}$ & 0.954304 & 1.148483 & $\$ 2,676.71$ & IRN.AX & 0.93012 & 0.980166 & $\$ 409.07$ & -0.00142 & $\mathbf{0 . 0 0 1 4 2 2}$ \\
$600309 . \mathrm{ss}$ & 0.949176 & 1.035379 & $\$ 6,034.06$ & EVN.AX & 0.916044 & 0.786781 & $\$ 902.82$ & -0.0031 & $\mathbf{0 . 0 0 3 1 0 1}$ \\
$600019 . \mathrm{SS}$ & 0.942489 & 1.091093 & $\$ 12,881.11$ & RIO.AX & 0.896701 & 1.335901 & $\$ 85,933.67$ & -0.00328 & $\mathbf{0 . 0 0 3 2 8 4}$ \\
$600601 . \mathrm{ss}$ & 0.925347 & 0.923437 & $\$ 796.68$ & WSA.AX & 0.895578 & 1.742187 & $\$ 574.78$ & 0.001893 & $\mathbf{0 . 0 0 1 8 9 3}$ \\
\hline
\end{tabular}

The STOCK is the Chinese and Australian stocks, SPEED is the speed of adjustment coefficient from the PAM, BETA is systematic risk, MCAP is market capitalisation in millions of Australian dollars. AVG SPEED is the average speed of adjustment coefficient from the Engle-Granger (1987) methodology and ABS is the absolute value of this coefficient.

The absolute value of the average speeds of adjustment from the cointegrating relationship is in the general direction of the speed of adjustments determined by the PAM, and thus are a check for robustness of the PAM.

Appendix D shows the diagnostics for the Markov switching strategy. 
Appendix D. Diagnostics of Markov switching strategy

\begin{tabular}{ccccccc}
\hline Stock Pair & Mean 1 & Mean 2 & SD 1 & SD 2 & P12 & P21 \\
\hline MDL/600050 & 6.810439 & 3.2869 & 0.971793 & 0.79552 & 0.008865 & 0.002406 \\
AGG/600879 & 2.858504 & 1.714695 & 0.601886 & 0.138947 & 0.007549 & 0.003805 \\
SPH/601600 & 1.427146 & 0.849946 & 0.31204 & 0.104029 & 0.004633 & 0.006415 \\
MGX/600688 & 1.003342 & 0.325797 & 0.14089 & 0.654455 & 0.009343 & 0.01484 \\
IGR/600028 & 0.467998 & -0.36026 & 0.281463 & 0.325254 & 0.007581 & 0.011384 \\
LYC/600104 & 0.664124 & -0.2754 & 0.194616 & 0.558716 & 0.006895 & 0.012729 \\
SDL/600887 & 2.706596 & 3.81018 & 0.949844 & 7.117577 & 0.005744 & 0.010869 \\
ARI/600100 & 1.061574 & 0.640752 & 0.166332 & 0.151908 & 0.007527 & 0.007696 \\
BSL/600011 & 3.931611 & 2.897475 & 0.440709 & 0.434213 & 0.012777 & 0.014606 \\
OZL/600026 & 1.843858 & 1.573111 & 0.400551 & 0.119543 & 0.019165 & 0.013573 \\
IMD/600717 & 1.134278 & 0.184592 & 0.245826 & 0.472374 & 0.00566 & 0.005725 \\
IRN/600177 & 1.364544 & 0.54841 & 2.349136 & 0.23079 & 0.010191 & 0.004923 \\
GRR/600362 & 0.658657 & 0.173981 & 0.145828 & 0.218259 & 0.005107 & 0.003012 \\
RIO/600019 & 2.240918 & 1.809272 & 0.164667 & 1.28881 & 0.023046 & 0.007598 \\
\hline
\end{tabular}

Stock Pair is the Chinese and Australian stock pair. Mean 1 is the mean value of regime state 1 . Mean 2 is the mean value of regime state 2. SD1 is the standard deviation of regime 1. SD 2 is the standard deviation of regime 2. P12 is the probability of being in regime 1 given that in the last state the value was in regime 2 . P21 is the probability of being in regime 2 given that previously the value was in state 1 .

Table 7 shows that it is clear that the regime switching model has split the data into two distinct samples; one with a high mean and one with a lower mean. Also apparent is the fact that the MDL/600050; AGG/600879; $\mathrm{SPH} / 600879$; ARI/600100; OZL/600026; IRN/600177 ratios are more variable at times when it is in the high mean regime, evidenced by their higher standard deviation. The low values of the P12 and P21 parameters indicate that the regimes are highly stable.

\section{Copyrights}

Copyright for this article is retained by the author(s), with first publication rights granted to the journal.

This is an open-access article distributed under the terms and conditions of the Creative Commons Attribution license (http://creativecommons.org/licenses/by/3.0/). 